\title{
A Novel Protection Method for Unsymmetrical Fault Detection of Overhead Transmission Line by Using DWT
}

\author{
M. Nandhini and S. Srinivasan
}

\begin{abstract}
Now a days, Most of the faults that occur on power systems are Unsymmetrical faults. Since any unsymmetrical fault causes unbalanced currents to flow in the system. The new protection method is based on the measurements and analysis of the currents, voltages, frequency. Discrete wavelet technique based fuzzy controller for identifying the transmission line faults. Normally the transients are non stationary waves. Wavelets are best choice to analyses the transient signals. Protection of transmission line is very important because it is a vital component between the generating stations and end users. Sudden changes in lines can cause very dangerous impact on power system. Many researches are even going on to enhance the techniques to solve these problems. Various types of faults, like line to ground, double line to ground and three phase faults. By this technique, the voltage and current are fast provided by means of MATLAB/Simulink model.
\end{abstract}

Keywords - Discrete Wavelet Technique (DWT) based Fuzzy Controller, Fault Detection, Transmission Line.

\section{INTRODUCTION}

$\mathrm{I}^{\mathrm{N}}$ $\mathrm{N}$ an electric power system, a fault or fault current is any abnormal electric current. For example, a short circuit is a fault in which current bypasses the normal load. An opencircuit fault occurs if a circuit is interrupted by some failure. In three-phase systems, a fault may involve one or more phases and ground, or may occur only between phasesIn a "ground fault" or "earth fault", current flows into the earth.[1] The prospective short-circuit current of a predictable fault can be calculated for most situations. In power systems, protective devices can detect fault conditions and operate circuit breakers and other devices to limit the loss of service due to a failure. The analysis of these types of faults is often simplified by using methods such as symmetrical components. [2]The design of systems to detect and interrupt power system faults is the main objective of power-system protection. Some power system faults there. they are, Transient fault , Persistent fault Symmetric fault, Asymmetric fault, Bolted fault, Realistic faults Arcing fault.

M. Nandhini, PG Scholar, Department of EEE, Vivekanandha College of Engineering For Women, Elayampalayam, Namakkal, Tamilnadu, India. E-mail:nandhinimani95@gmail.com

S. Srinivasan, AP/Department of EEE, Vivekanandha College of Engineering For Women, Elayampalayam, Namakkal, Tamilnadu, India. E-mail:srivaas131985@gmail.com

DOI: 10.9756/BIJMMI.2214
Power transmission systems use protection relays to detect and clear different types of faults as soon as possible with total selectivity in order to minimize damages in the power elements that form the electrical power network as well as to reduce the instability in the network caused by such faults.[3] In those systems that supply important loads like cities or factories, there are many overhead-cable transition stations that supply those loads. Some transmission lines have two different parts, one is the underground cable side and the other one is the overhead side [4].

A transient fault is a fault that is no longer present if power is disconnected for a short time and then restored[5]or an insulation fault which only temporarily affects a device's dielectric properties which are restored after a short time. Many faults in overhead power lines are transient in nature. When a fault occurs, equipment used for power system protection operate to isolate the area of the fault. A transient fault will then clear and the power-line can be returned to service.[6]

Unsymmetrical fault which occurs between one or two phases and/or the ground for example between a phase and the ground, between two phases or between two phases and the ground. An asymmetric or unbalanced fault does not affect each of the three phases equally.

\section{OVERHEAD TRANSMISSION LINE}

An overhead power line is a structure used in electric power transmission and distribution to transmit electrical energy along large distances. It consists of one or more conductors (commonly multiples of three) suspended by towers or poles. [7]Since most of the insulation is provided by air, overhead power lines are generally the lowest-cost method of power transmission for large quantities of electric energy.

A transmission line is a specialized cable or other structure designed to conduct alternating current of radio frequency, that is, currents with a frequency high enough that their wave nature must be taken into account. in that transmission line single line to ground fault, double line to ground fault, three phase fault are occur.[9]Transmission lines use specialized construction, and impedance matching, to carry electromagnetic signals with minimal reflections and power losses. The distinguishing feature of most transmission lines is that they have uniform cross sectional dimensions along their length, giving them a uniform impedance, called the characteristic impedance, to prevent reflections. Types of transmission line include parallel line (ladder line, twisted 
pair), coaxial cable, and planar transmission lines such as strip line and micro strip[10].

\section{Discrete WAVELET Technique Based Fuzzy CONTROLLER}

Discrete wavelet transforms (DWTs), including the maximal overlap discrete wavelet transform (MODWT), and analyze signals and images into progressively finer octave bands. [11]This multi resolution analysis enables you to detect patterns that are not visible in the raw data. You can use wavelets to obtain multistage variance estimates of your signal or measure the multistage correlation between two signals. You can also reconstruct signal (1-D) and image (2D) approximations that retain only desired features, and compare the distribution of energy in signals across frequency bands. Wavelet packets provide a family of transforms that partition the frequency content of signals and images into progressively finer equal-width intervals.

The Wavelet Toolbox functions to analyze signals and images using decimated (down sampled) and non decimated wavelet transform. Use multi signal analysis to reveal dependencies across multiple signals. Determine the optimal wavelet packet transform for a signal or image. Use the wavelet packet spectrum to obtain a time-frequency analysis of a signal. Use lifting functions to implement perfect reconstruction filter banks with specific properties.

The transform of a signal is just another form of representing the signal. It does not change the information content present in the signal. The Discrete Wavelet Transform provides a compact representation of a signal in time and frequency that can be computed efficiently. In wavelet analysis, we often speak of approximations and details. The approximations are the high-scale, low-frequency components of the signal. The details are the low scale, high frequency components The DWT is defined by the following equation.
Where $\varphi(t)$ is a time function with finite energy and fast decay called the mother wavelet Equation(1) shows that it is possible to build a wavelet for any function by dilating the function $\varphi(\mathrm{t})$ with a coefficient, and translating the resulting function on a grid whose interval is proportional. The DWT analysis can be performed using a fast, pyramidal algorithm related to multi rate filter banks. In the pyramidal algorithm the signal is analyzed at different frequency bands with different resolution by decomposing the signal into a coarse approximation and detail information. The coarse approximation is then further decomposed using the same wavelet decomposition step. This is achieved by successive high- pass [n] and low-pass h[n] filtering of the time domain signal and is defined by the following equations:

$$
\begin{aligned}
& \operatorname{yhigh}[k]=\sum_{n k} x(n) g(n k-n) \\
& y \operatorname{low}[k]=\sum_{n k} x(n) g(n k=n)
\end{aligned}
$$

The outputs of the high pass (g ) and low pass (h) filters, respectively after down sampling.

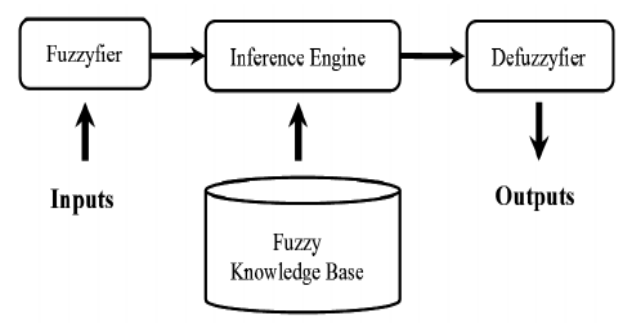

Figure 1: General Fuzzy Control Diagram

Simply put, it is fuzzy code designed to control something, usually mechanical. They can be in software or hardware and can be used in anything from small circuits to large mainframes.

$$
W(j, k)=\sum j \sum_{K} X(K) 2^{-\frac{J}{2}} \emptyset\left(2^{-\frac{J}{2}} n-k\right)
$$

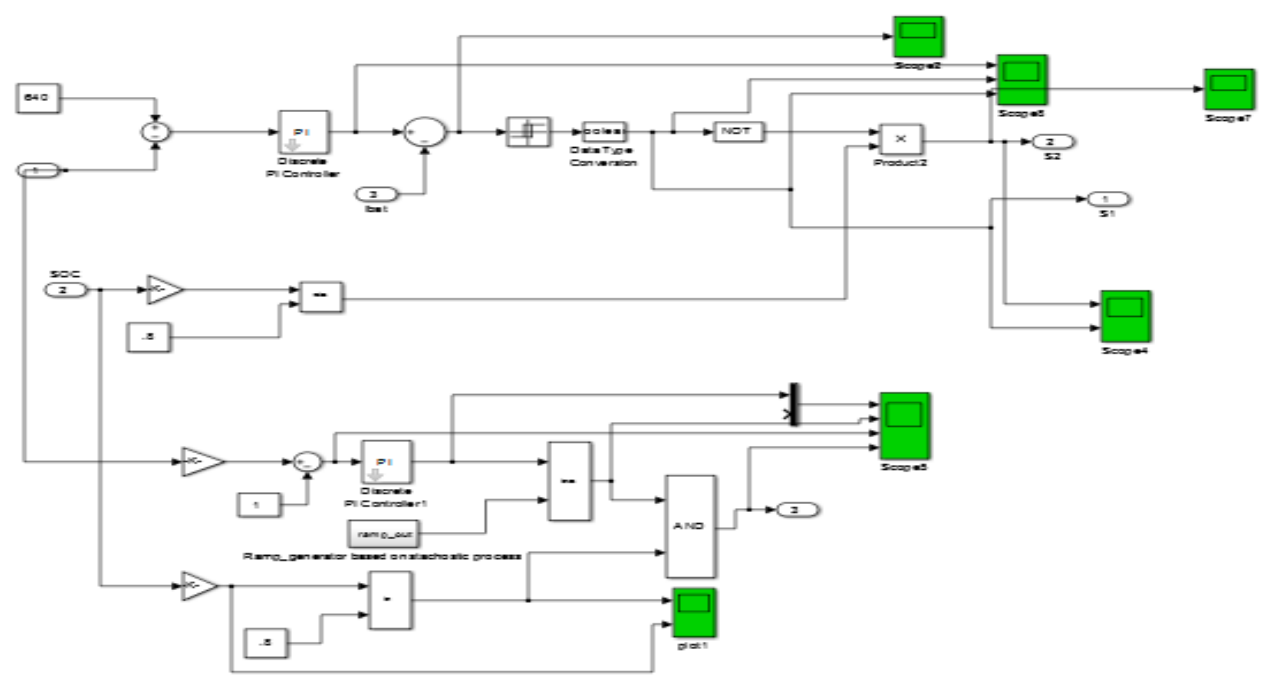

Figure 2: Control Technique DWT based Fuzzy Control 


\section{Fault Detection System}

A substation is a part of an electrical generation, transmission, and distribution system. Substations transform voltage from high to low, or the reverse, or perform any of several other important functions. [12]Between the generating station and consumer, electric power may flow through several substations at different voltage levels. A substation may include transformers to change voltage levels between high transmission voltages and lower distribution voltages, or at the interconnection of two different transmission voltages. [13]A circuit breaker is an automatically operated electrical switch designed to protect an electrical circuit from damage caused by excess current, typically resulting from an overload or short circuit. Its basic function is to interrupt current flow after a fault is detected.[14]

The circuit breaker must firstly detect a fault condition. the conditions are switching of phase A, switching of phase B, Switching of c. [15]The Three-Phase Breaker block implements a three-phase circuit breaker where the opening and closing times can be controlled either from an external Simulink signal (external control mode), or from an internal control timer (internal control mode).

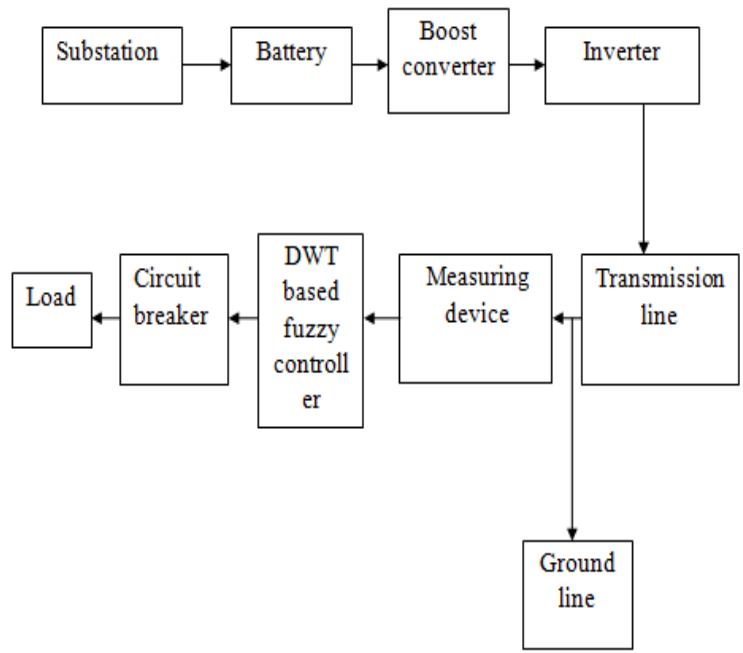

Figure 3: Fault Detection Proposed Block Diagram

\section{SimUlation RESUlts}

MATLAB (matrix laboratory) is a numerical computing environment and fourth-generation programming language. Developed by Math works, MATLAB allows matrix manipulation, creation of user interfaces and interfacing with programs written in other languages.

\section{A. Simulink Circuit Model}

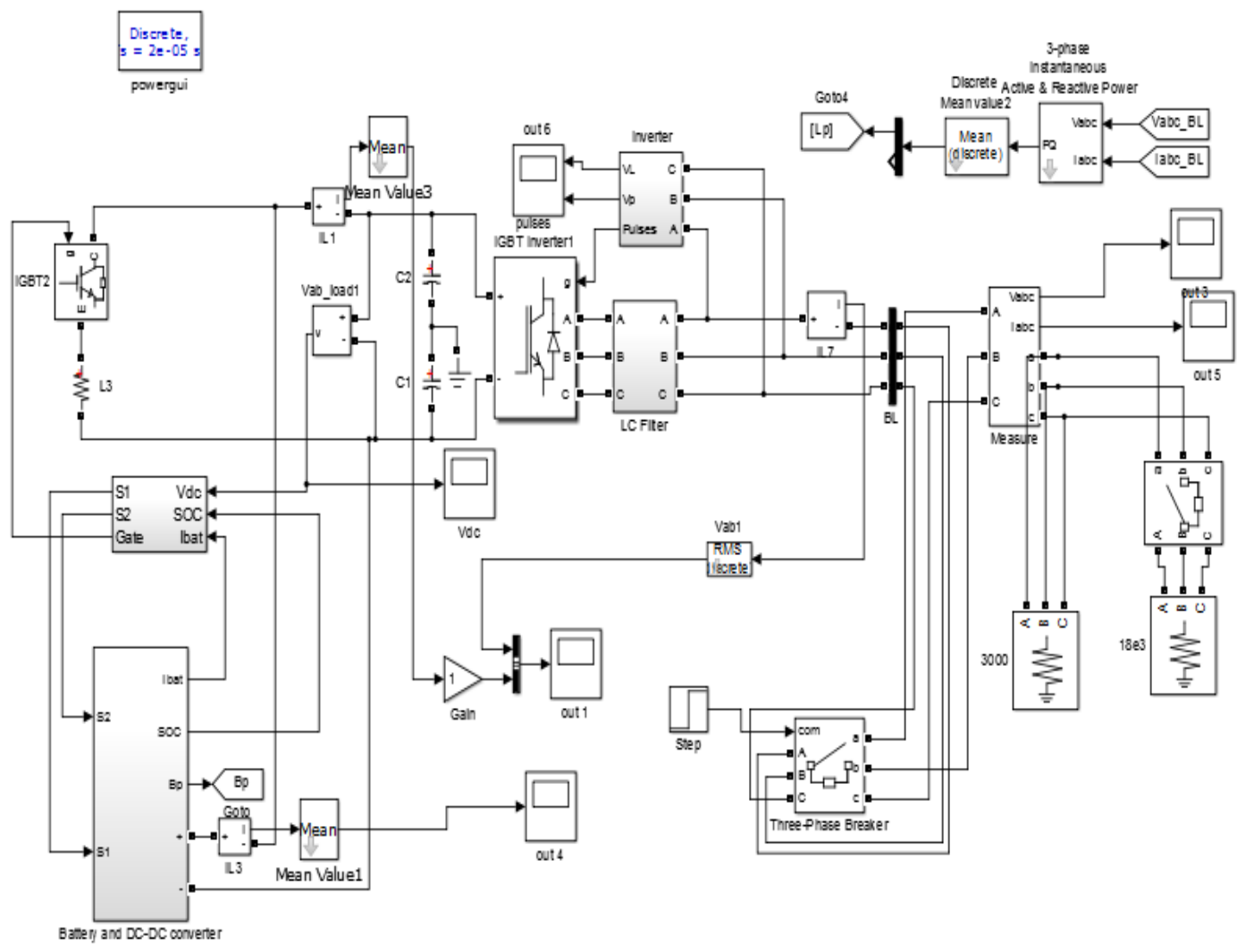

Figure 4: Simulink Circuit Model 


\section{B. Simulation Results}

waveforms are indicate faulty phase in the transmission line.

Fig 5,6,7 are output waveforms of single line to ground fault, double line to ground fault, three phase fault. the

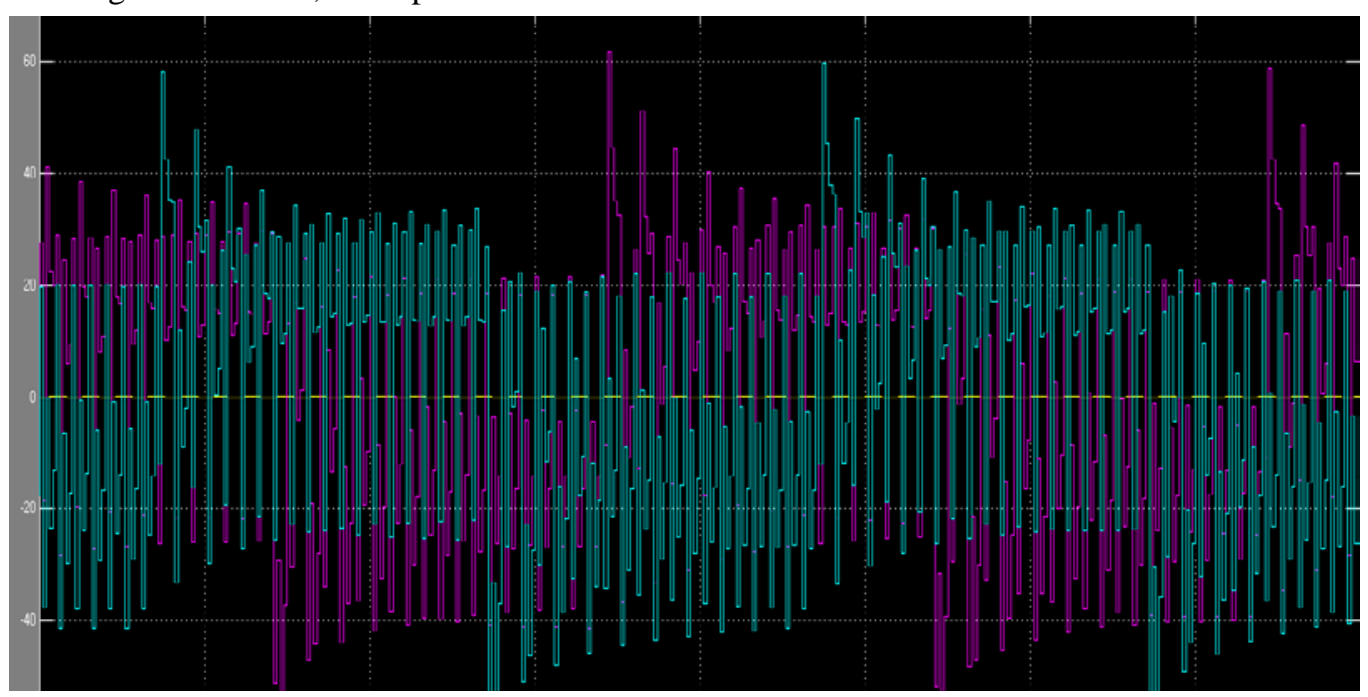

Figure: 5 Single Line to Ground Fault

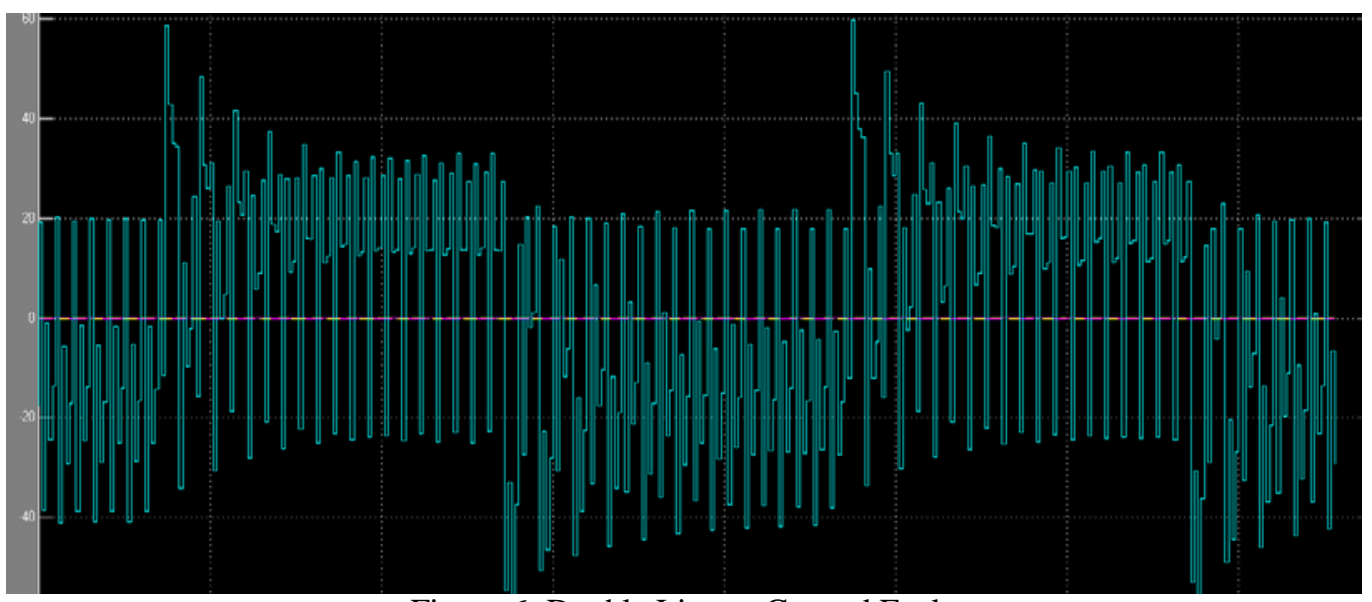

Figure 6: Double Line to Ground Fault

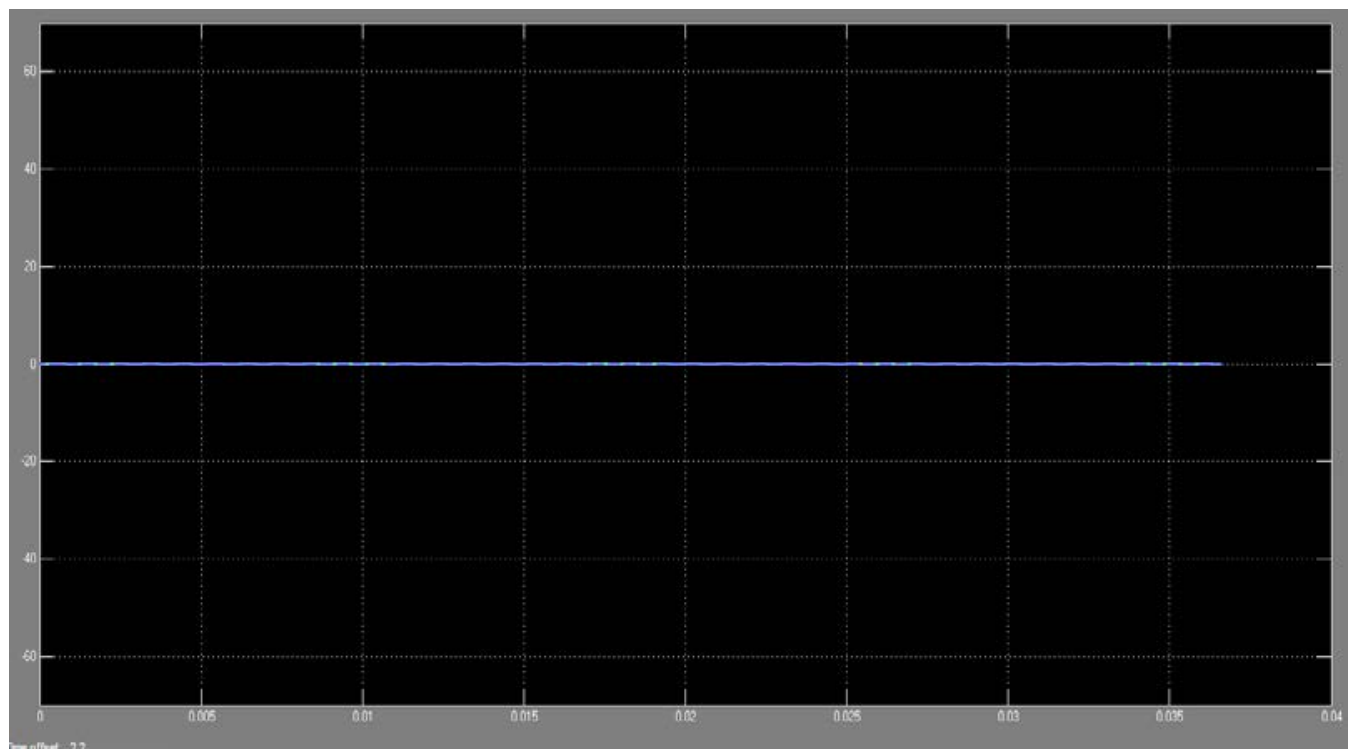

Figure 7: Three Phase Fault 


\section{CONCLUSION}

In this project, the new protection method is based on the measurements and analysis of the currents, voltages. Discrete wavelet technique for identifying the transmission line faults. Faults are line to ground, double line to ground and three phase faults. WT used to extract information from three phase current signals and to process the high frequency details to derive information about the fault. Simulation results show the logic is fully deterministic, easy to understand, and also the classifier operation is fast and reliable. Simulation results are verified under various fault cases using MATLAB/simulink.

\section{FUTURE WORK}

Adaptive Neuro Fuzzy Interface System(ANFIS) is implemented for future work instead of DWT(Discrete wavelet technique) based fuzzy controller. by using this, the power factor is connected on the load side with the measured voltage values from the transmission line against single line to ground, double line, three phase fault.

\section{REFERENCES}

[1] P.N. Bychkov, I.K. Zabrodina and V.S. Shlapak, "Insulation contamination of overhead transmission lines by extreme service conditions”, IEEE Transactions on Dielectrics and Electrical Insulation, Vol. 23, No. 1, Pp. 288-293, 2016.

[2] A. Birajdar and S. Tajane, "Modelling and simulation of transmission line to detect single line to ground fault location", IEEE $1^{\text {st }}$ International Conference on Power Electronics, Intelligent Control and Energy Systems (ICPEICES), Delhi, 2016.

[3] N. Tleis, "Power systems modelling and fault analysis", newness, Oxford, 2008.

[4] M.M. Saha, J. Izykowsky and E. Rosolowsky, "Fault location on power system networks”, Springer-verlag Berlin, 2009.

[5] N. Kagan, N.M. Matsuo, E.L. Ferrari and V. Vega-García, "Computerized System for Detection of High Impedance Faults in MV Overhead Distribution Lines", 17th International Conference on Harmonics and Quality of Power (ICHQP), Pp. 992-997.

[6] C. Subramani, A. Jimoh, M. Sudheesh and I.E. Davidson, "Fault investigation methods on power transmission line: A comparative study”, IEEE PES Power Africa, Livingstone, 2016.

[7] A. Fedotov, Rustem A. Zyanov and G. Vagapov, "Detection of Places of Single-Phase Ground Fault by Frequency of the Resonance", International Scientific Conference on Power and Electrical Engineering of Riga Technical University (RTUCON), 2016.

[8] F.V. Santos, N.S.D. Lopes and B.A. Brito, "High impedance fault identification on distribution networks", on IEEE Transactions on Power Delivery”, IEEE transactions on power delivery, 2016.

[9] A. Lei, X. Dong, S. Shi and B. Wang, "A novel current travelling wave based single-ended fault location method for locating single phase- toground fault of transmission line”, 50th International Universities Power Engineering Conference (UPEC), Stoke on Trent, 2015.

[10] C. Yao, H. Wu, Y. Long, Y. Mi, Y. Ma, Y. Shen and L. Wang, “A Novel Method to Locate a Fault of Transmission Line by Shielding Failure”, IEEE Transactions on Dielectrics and Electrical Insulation, Vol. 21, No. 4, 2014.

[11] R. Haddadi, E. Abdelmounim and M. Elhanine, "Discrete Wavelet Transform Based Algorithm for Recognition of QRS Complexes”, In World of Computer Science and Information Technology Journal (WCSIT), Vol. 4, No. 9, 127-132, 2014.

[12] A. De Souza Gomes, M.A. Costa, T.G.A. De Faria and W.M. Caminhas, "Detection and Classification of Faults in Power Transmission Lines Using Functional Analysis and Computational Intelligence”, IEEE Transactions on Power Delivery, Vol. 28, No. 3, Pp. 1402-1413, 2013.
[13] S. Mangion, P.L. Buccheri and M.L. Mineo, "Efficient modelling of a combined overhead cable line for grounding-system analysis", IEEE Transmission and Distribution Conference and Exposition: Latin America, Pp. 1-6, 2013.

[14] S.H. Horowitz and A.G. Phadke, "Power system relaying, third edition”, wiley. New York, 2008.

[15] H. Renwang, "A New Approach to the Calculation of Reclosing Time for Adaptive Auto-reclosure", IEEE Conference on Power and Energy Engineering (APPEEC), 2010 Asia-Pacific, Pp. 1-2, 2010.

[16] J. Izykowski, E. Rosolowski and M. Saha, "Post-fault analysis of operation of distance protective relays of power transmission lines", IEEE Power Engineering Society General Meeting, Montreal, Que., 2006.

[17] P. Li, B.H. Zhang, Z.G. Hao, Y.F. Rao, Y.T. Wang, Z.Q. Bo, A. Klimek, Q. Zhao and W. He, "Optimal Reclosing Time of Transmission Lines and its Application in Real Power System", 9th International Conference Presented at the Developments in Power System Protection, UK, Vol. 110, No. 115, Pp. 17-20, 2008.

[18] K.M. Silva, B.A. Souza and N.S.D. Brito, "Fault detection and classification in transmission lines based on wavelet transform and ANN”, IEEE Trans. Power Del., Vol. 21, No. 4, Pp. 2058--2063, 2006.

[19] O.A.S. Youssef, "New algorithm to phase selection based on wavelet transforms”, IEEE Trans. Power Del., Vol. 17, No. 3, Pp. 908--914, 2002. 